\author{
Barbora Chovancová \\ Masaryk University \\ Czech Republic
}

\title{
MEDIATION IN LEGAL ENGLISH TEACHING
}

\begin{abstract}
Mediation is a language activity that has been unjustly neglected when preparing law students for their future professional careers. When trained in a professional context, students need to develop and improve complex communicative skills. These include not only the traditional language skills such as reading, writing, listening and speaking, but also more advanced skills such as summarizing, providing definitions, changing registers etc. All these are involved in the students' acquisition of 'soft skills' that are particularly important for students of law since much of their future work involves interpersonal lawyer-client interaction. This article argues that mediation is a crucial (though previously underestimated) skill and that law-oriented ESP instruction should provide training aimed at developing this skill. Showing a practical application of this approach, the paper demonstrates that mediation can be successfully integrated in the legal English syllabus and make the learning of legal English more effective.
\end{abstract}

Keywords: English for Specific Purposes (ESP); legal English; mediation; ELT methodology; applied linguistics

\section{Introduction}

Traditional accounts of ELT/ESP methodology tend to be constructed around a focus on the four basic language skills: reading, writing, speaking and listening (cf. Howatt and Widdowson 2004[1984]). For each of these skills, there is an extensive methodological background to help teachers make the classroom situation maximally effective for their students (cf. UsóJuan and Martínez-Flor 2006) and to make students reach sufficient communicative competence (cf. Dörnyei 2007). It has been observed in the early stages of research into English for Specific Purposes (ESP) that ESP is more than just learning a 'specialized variety' of English (Hutchinson and Waters 1980). In the 1980s, there has been a shift away from the teaching of the structural aspects of language to communication and a systematic atten- 


\section{Barbora Chovancová}

tion to the development of students' communicative skills. As Dudley-Evans and St. John (1998) point out, the skills-approach to language teaching was then complemented with the emergence of the learning-centred approach in the late 1980s (cf. Nunan 1988). This has enhanced the role of individual students, stressing the need to rely on their prior academic/professional experience in order to achieve the target goal.

Effective ESP instruction has come to rely on needs analysis as an inseparable part of any teacher involved in syllabus construction (Hutchinson and Waters 1987; Swales 2000; Long 2005; Basturkmen 2013). The analysis of students' future needs in the second language is a pre-requisite for the formulation of realistic targets. ESP targets can be efficiently formulated not only on the basis of the language teachers' assessment/observation of reallife situations and pre-service students' statements on their self-perceived needs but also on the basis of former graduates' experience from the reallife world of work in what can be referred to as 'transferred needs analysis' (Chovancová 2013, 2014). In this way, valuable information can be obtained to modify existing syllabi so that they reflect the workplace realities as close as possible. In the area of legal English teaching, for instance, it emerges that pre-service students are unable to foresee just how crucial it is to be able to process texts efficiently and how to communicate information to others, including non-experts. It appears that the extent to which the four basic skills are needed in lawyer-client communication, both in international and national contexts, is something that pre-service students find hard to imagine. This conforms to an observation made by Dudley-Evans and St. John concerning some unexpected connections between the skills: “...even though students may only need to read textbooks and articles in their field, it may be that oral practice will help them reach that end" (1998: 26; original emphasis).

One of the crucial communicative skills that future lawyers will need in their careers is mediation. This is an actual communicative skill, i.e. not a language skill in the traditional conception found in applied linguistics literature. Mediation is one of the "soft skills" that modern professionals increasingly need to be equipped with in the modern globalized world. In case of legal professionals, this skill consists of the lawyers' ability to provide their clients with information in such a form and manner that the clients may not only understand but, based on the information received, actually be able to make informed decisions. The concept of mediation originates in translation science (cf. Valero-Garcés n.d.; Pym 2012) but it has recently started to be applied in language learning as well, particularly on account of the inclusion of this skill in CEFR (see below). 
While the issue of translating and interpreting legal content has been dealt with by numerous scholars (cf. Šarčević 1997; Chromá 2004; Alcaraz and Hughes 2014), the concept of mediation has so far received much less attention. Because of the lack of theoretical studies, LSP (Language for Specific Purposes) methodology has not yet progressed sufficiently in order to incorporate this communicative skill in LSP classrooms and turn it into the subject of focussed practice. This article aims to delimit the area, describe the concept of mediation, and suggest some suitable ways of how the practice of the skill of mediation can be brought into the LSP classroom. Because the author's background is in teaching legal English, this will be illustrated with examples from this area of ESP. The observations, however, are freely transferable to other areas of LSP as well.

\section{Mediation as a specific communicative skill}

Mediation is a term that carries different meanings in different fields. For lawyers, the primary meaning is probably the one that appears in the common collocation "litigation, mediation, and arbitration". In that sense, mediation equals "alternative dispute resolution (ADR)", i.e. a method of settling disputes between disagreeing parties out of court. In applied linguistics, the concept of mediation is different: it refers to a communicative skill that enables a person to overcome a communication gap - to provide information in a way that the recipient can not only understand but, based on the understanding, also use to make an informed decision. Mediation needs to be distinguished from translation and interpretation, with which it is sometimes confused. It is important to acknowledge that mediation concerns the processing and transmission of information not only between different language systems ("interlanguage mediation") but also between different levels of expertise ("intralanguage mediation").

The concept of mediation features in Common European Framework of Reference for Languages (CEFR). However, it is not extensively elaborated there and its definition is somewhat insufficient. This shortcoming is, however, being remedied, as there is a team of CEFR experts currently working to develop new descriptors for mediation.

\section{What is mediation}

The guidelines to Council of Europe's Common European Framework of Reference for Languages ("CEFR"), which describes achievements of learners of foreign languages from 2001, define mediation as both written and oral activities that: 
make communication possible between persons who are unable, for whatever reason, to communicate with each other directly. Translation or interpretation, a paraphrase, summary or record, provides for a third party a (re)formulation of a source text to which this third party does not have direct access. (CEFR, 14)

This definition captures two aspects of communication in legal contexts. First, legal professionals frequently act as genuine mediators between clients. Second, they also mediate, for the benefit of their clients, diverse legal texts, regulations and judgments that have institutional authors and may not be meant for specific recipients. Interestingly enough, the above definition does not limit the meaning of mediation to the rendering of meanings from one language to another ("interlanguage mediation"). Thus, mediation can involve communication (interpretation, paraphrase) entirely in one's mother tongue (CEFR, 57). Such intralanguage mediation can, therefore, also cover expert-to-lay communication, with the mediator changing or adapting linguistic register in order to explain certain terms and concepts. In this way, the mediator helps the recipient achieve "literacy" or attain the "capacity to use information in order to make specific informed decisions" (Pym 2015).

While Pym uses examples from the area of health services (where an interpreter-mediator mediates information between a medical professional and a patient), the concept of mediation can be equally well applied to the legal world. Thus, for instance, both a lawyer-client interview (orally presented) and a letter to a client (in its written form) could be viewed as specific forms of mediation, with the expert presenting information to a layperson in a way that the latter can understand, apply to his or her particular situation, and become aware of the consequences that his or her decision may lead to. This kind of communicative skill may, and should be, trained by the subject teachers in the students' mother tongue in the course of their legal studies. When this process involves the rendering of information from a student's second (non-native) language (such as English) or between two different languages, the communicative skill of mediation will be in the realm of legal English instructors, which also holds for some situations where instruction occurs in the context of content and language-integrated learning (CLIL, cf. Do et al. 2010; Mehisto et al. 2008).

The process of mediation assigns a distinct role to the communicator. This role relates to the functions performed in the process: the monitoring, the facilitation and the negotiation of meanings. In this sense, the "mediator" is defined by Dendrinos (2011) as follows: 
- "a social actor who monitors the process of interaction and acts when some type of intervention is required in order to help the communicative process and sometimes to influence the outcome;

- a facilitator in social events during which two or more parties interacting are experiencing a communication breakdown or when there is a communication gap between them;

- a meaning negotiator operating as a meaning-making agent especially when s/he intervenes in situations which require reconciliation, settlement or compromise of meanings." (Dendrinos, 2011)

Clearly, the skill of mediation places some specific demands on the mediator, going beyond a mere linguistic proficiency in the target language.

\section{Mediation vs. translation and interpretation}

The CEFR team are currently working on sets of illustrative descriptors for mediation. This effort should culminate, in the foreseeable future, in a more detailed, and maybe even slightly modified, perspective on what mediation involves. In the 2001 version of CEFR, mediation is taken to be equal to simultaneous, consecutive or informal interpretation (in is oral form) and exact and literary translation, summarising gist or paraphrasing (in its written form). This is a somewhat problematic view. As pointed out by Dendrinos (2011: 16), simultaneous and consecutive interpretation, as well as literary translation, are professional skills that are not trained in classes where English is taught as a foreign language. She aptly argues that:

...mediation is altogether different from professional translation and mediation. I view it as a form of everyday social practice which involves meaningmaking agents (that is, event participants who create social meanings during the process), in acts of communication that require negotiation of meaning and relaying of information across the same or different languages. (2011: 16)

Referring to a Greek examination expert prof. Vasso Tocatlidou, Dendrinos explains her perspective on the difference between translators/interpreters and mediators as follows:

Translators, like interpreters, she says, appear nowhere in the discourse produced; they do not express their personal take on an issue or their opinion and they are not interlocutors in a communicative exchange. They remain true to the original text which they are required to respect. They do not have the 'right' to change the discourse, genre or register of the text they are producing (e.g., an announcement, a decision, a speech) nor resort to reported speech. Mediators, on the other hand, participate in the communicative event, become interlocutors and turn a two way into a three way exchange, interpreting and 


\section{Barbora Chovancová}

making choices they think are useful for the other participants. They choose which messages to transfer and which bits of information to relay - making a judgement call as to what might interest or be relevant to the other participants. The information relayed is often in the form of a report, which includes only those pieces of information considered relevant for a specific event by the mediator. What is reported depends exclusively on ... the context of situation and the task at hand. (2011: 17)

This indicates that mediation is fundamentally different from translation/interpretation, though all these processes may bear some surface resemblance. Mediation involves the active involvement of the mediator, who modifies the mediated content for the recipient's benefit. In that sense, mediation can be seen as more complex than translation/interpretation because the mediator needs to take into account the effect of his message on the recipient, having to monitor the reception and, if necessary, modify the form of his communication in the process.

\section{Mediation and legal English}

Translators and interpreters do not constitute a homogeneous group. Some legal translation and interpretation requires quite exact and precise work, sometimes provided by sworn or authorized translators who are professionally "qualified to work for the various national justice systems, either in the courts or in production of translations that are legally valid" (Pym, p. 7). Not everybody is permitted to perform this kind of work: access to the profession is "regulated by specifically juridical institutions, mostly in the form of national laws restricting whose work is valid" (ibid.). However, some other forms of legal translation and interpreting exercise much more freedom. This is the case of translators with immigration communities who have embraced the term "mediation" to describe their own practice. In an article on translation in Spanish public services dealing with immigrants, Valero-Garcés sees professional translators and interpreters as cultural mediators who "need to develop not only linguistic skills, but also cultural and anthropological abilities" (Valero-Garcés, n.d.: 5).

In their communication with clients, lawyers are likely to be asked to explain a legal situation, or consequences thereof, that fall within the scope of their expertise. The clients will not need to have a relevant law translated for them. Rather, they will want to know what it means for them in their unique situations. The work of the lawyer is thus that of a mediator rather than of a translator/interpreter. 


\section{Textbooks}

The methodology of teaching English as a foreign language traditionally does not address the problem of translation from foreign languages into English and vice versa. This is the result of partly the dominance of the communicative approach in past couple of decades and partly the general backgrounding of the English non-native speaker from the teaching context. As pointed out by Dendrinos, even though "having the skills to mediate between the L1 and English ... constitutes a basic need for the learners or EFL users, ... the mainstream politics of English didactics ... for many years kept the L1 out of the EFL classroom" (2011: 13). This is linked to the fact that the role of the native speaker has been overvalued while that of the non-native speaker undervalued (14).

In case of English for legal purposes, the situation is slightly different. Here, the need for translation has traditionally been felt much more strongly. In locally produced materials, translation has tended to be included. An example of this may be the textbooks for Czech law students by Marta Chromá (2011a, 2011b). In her New Introduction to Legal English (as well as in the earlier editions), there are numerous translation tasks for students. The translation exercises are included in the final sections of each unit (Section B - Word Study and/or Section C - Translating Legal Information). They vary from translating individual sentences related to the topic of the unit, short extracts from legal texts, sections of Acts to parts of contracts (e.g. an agreement to make a contract of sale).

Textbooks designed by native speakers do not include translations from English to the students' mother tongue. The reason is obvious: the translation could not be assessed by native speaker teachers. That is also the case with international legal English exams like ILEC or TOLES, where assessing translation is not possible and/or practical.

Nevertheless, textbooks published in English speaking countries do include activities that fall within the scope of the communicative practice of "mediation". This involves professional communication with clients, e.g. in the form of letters to clients or in the format of role-play, where the student playing the role of the lawyer needs to inform the client about a particular legal situation. The student in the lawyer role will need to explain the relevant terms and outline possible consequences. In this process, the student may need to change register, modify sentence structure, etc.

Not every role-play, nonetheless, "mediates" information in the sense of the term as defined above. Mediation does not take place where students, when role-playing the lawyer, make information up or draw on their general 


\section{Barbora Chovancová}

knowledge. By contrast, if they need to relay relevant legal information that they obtain from a legal text, even in their native language, with the aim of adequately informing the other student and enabling him or her to make a decision in their role of the client, this constitutes an example of mediation.

Let me illustrate this with several exercises from textbooks in order to point out the difference between mediation and non-mediation. For example, a speaking task from the textbook International Legal English gives the following instructions: " 1 . Describe the different types of courts in your jurisdiction and the areas of law they deal with. 2. Select one type of court in your jurisdiction and explain what kinds of case it deals with" (KroisLindner and Translegal 2006: 11). In this exercise, students will be providing information for their peers rather than having to mediate the content for the benefit of clients, adjusting register, etc. In this case, mediation skills are actually not at stake.

Mediation can be practiced in exercises aimed at the development of receptive skills, e.g. in the form of listening comprehension exercises. An interesting example of mediation occurs in Introduction to Legal English, which features the following explanation of legal terms between two legal systems:

Ms Fialová: First, can I check what kind of agreement you wanted? Basically, it comes down to the Czech equivalent of the periodic tenancy of the shorthold tenancy. There are other options available, but I wouldn't recommend them for your circumstances.

Ms Cervera: The periodic is the one that is automatically renewed at the end of the tenancy period, right?

Ms Fialová: Yes, and the shorthold guarantees a fixed period, after which you need to sign a new agreement. It runs from month to month once the fixed term has passed.

Ms Cervera: OK. I think that's what we've decided would be best.

(Krois-Linder et al., 2008: 134)

The expert, Ms Fialová, explains the relevant terms, making a choice of which term to include and which not (There are other options available, but I wouldn't recommend them for your circumstances.). Thus, she leaves it to the client to make an informed decision, i.e. to choose which type of tenancy she wants to be used in her agreement. This can serve as a model for role plays on communication between a lawyer and a well-informed client (a negotiation of meaning takes place (The periodic is the one that is automatically renewed at the end of the tenancy period, right?). 


\section{Mediation and lawyers' everyday work}

The question of whether lawyers will need mediation in their daily work with clients can be answered in the affirmative. CEFR points out that mediation occupies "an important place in the normal linguistic functioning of our societies" (CEFR, 14) and it does not necessarily need to involve rendering meaning from two different languages (CEFR, 54). Thus, a simple lawyer-client interaction in a legal consultation could be described as "mediation" where the lawyer fills the information gap between the source text (relevant law) and the client who needs the information to make a decision to act in a certain way.

In their professional capacity, lawyers frequently provide explanations of unknown terms, give interpretations of laws, and outline possible consequences that the legal framework or situation may have for their clients. This can all happen in the native language. A classic example of a need for interlanguage mediation concerns legalese, i.e. the concocted and overly complicated language used by lawyers and found in legal texts that is hard to understand by the general public. Some of the simplified definitions of legalese half-jokingly say that it is a kind of jargon that non-lawyers find hard to understand, cf.:

Legalese is the jargon used by lawyers especially in legal documents. It comprises of legal terms combined in lengthy sentences, complex vocabulary and high abstraction. It generally results in complexity and confusion for ordinary people.

(http://definitions.uslegal.com/l/legalese/)

Though legalese has to a certain extent been replaced by plain English, lawyers still need to mediate the content of terms, laws and documents to laypeople. As stated previously, however, this type of mediation is not something that students of law tend to encounter in their classes. This skill has not been the subject of Legal English teaching. The mediation of information in the native tongue of the lawyer to English or vice versa, as well as mediation in English, should have a firm position in the Legal English classroom.

Law students will undoubtedly give a positive answer when asked to mediate relevant law/legal consequences of a situation to a client from a different country. The lawyer may use a source text in the native language or the official translation, but in either case they will be mediating the gist of the law and the possible outcomes relevant to the client's situation. Apart from legal aspects, culture-dependent contexts may need to be included and 
interpreted as well, particularly if the client comes from the Common and not Civil law tradition.

\section{Mediation in ELP practice}

\section{Sample activities}

A common criticism of legal English textbooks produced by native speakers is that they do not reflect the situation in the students' native countries. While in the past the textbooks usually focused on Common Law, the current practice is to encompass International law (or more specifically European Civil law), very often in business contexts. This problem is sometimes addressed by material writers who increasingly rely on the local, national law (cf. the recent textbook Legal English by Halina Sierocka, who based the textbook on Polish law).

This problem may be overcome by teachers/material writers devising simple tasks that can be added to supplement existing textbooks. One of the ways of doing this is to include a law taken from the relevant jurisdiction and create a scenario in which a Lawyer needs to supply a Client with information that the latter needs to obtain in order to take some kind of further action. An example of such an activity, designed to meet the needs of Czech law students, is provided below.

\section{Background}

Students studying law at Czech public universities are all required to take compulsory Second Language classes for Lawyers at the beginning of their studies, when they have only a very vague idea of what law and being a lawyer entails. It is therefore necessary to design believable scenarios in which the students may picture themselves. It is also recommended to provide the students with the relevant legislation and other legal sources.

\section{Scenario}

\section{Theft in a Hotel Room}

An example of a situation that constructs a believable scenario is, for instance, the provision of assistance to a tourist in distress. Figure 1 shows a page from teaching materials that give instructions to students ready to role-play interaction between a lawyer and a client with respect to the fictional scenario of 'a theft in a hotel room'. 


\section{Hotel Room Theft (lawyer-client interview)}

Task: You work as a novice lawyer in a prominent law firm. You have your first client coming for an interview and your supervisor is going to assess your performance during the interview. Do your best! Good luck!

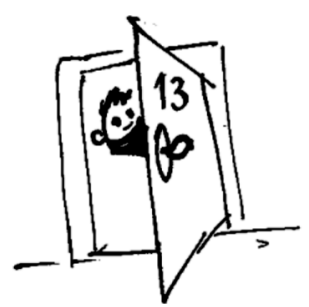

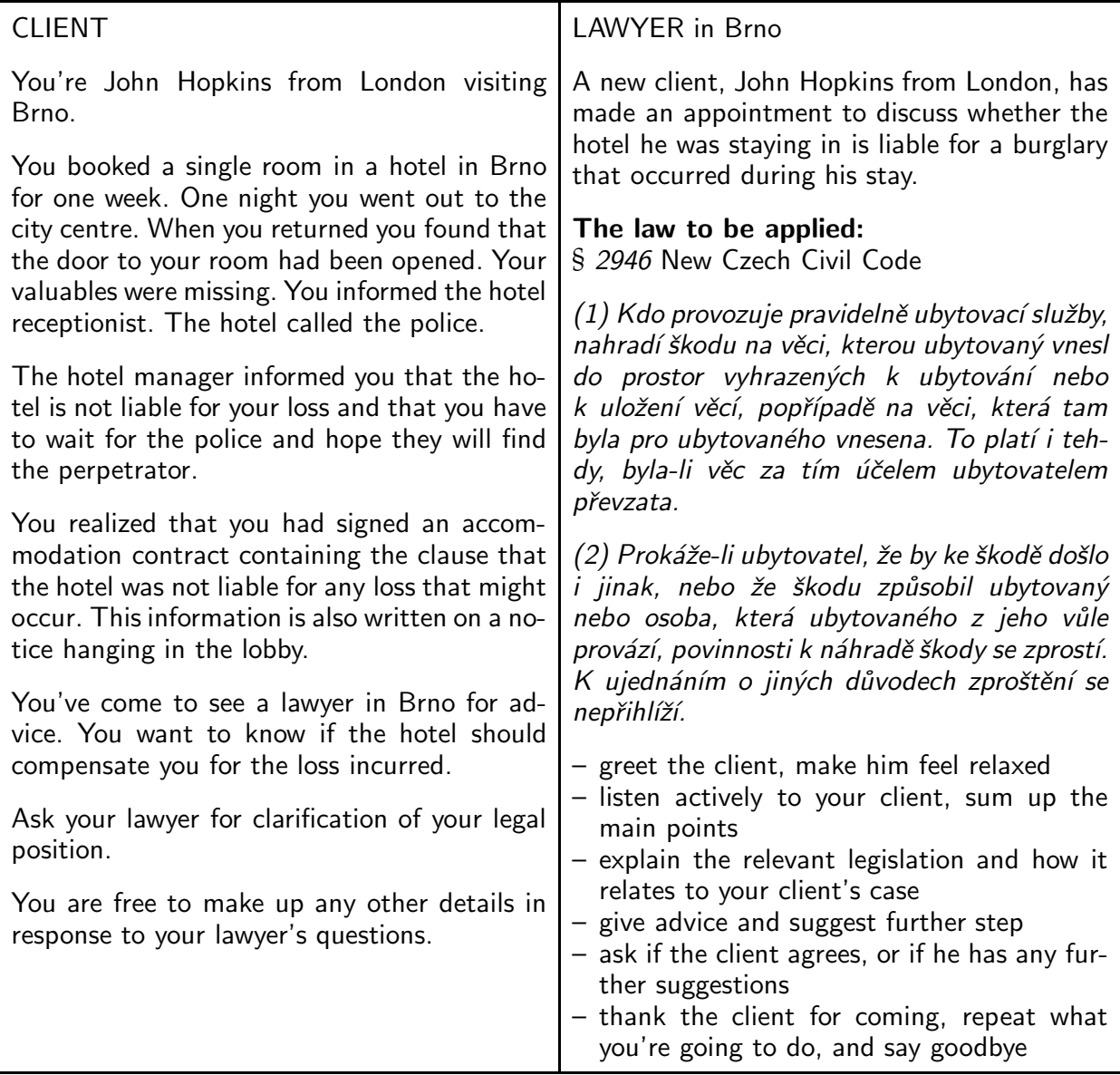

Figure 1. Example of an effective mediation practice activity

\section{Sources: Relevant Law}

The theoretical framework for mediation proposed by CEFR suggests that several steps be taken into account during the process of mediation (see Figure 2). All these steps are applicable for the teaching situation in ELP 
classroom and they can be suitably incorporated in the sample activity proposes above, cf.:

\begin{tabular}{|l|l|}
\hline Planning & $\begin{array}{l}\text { Developing background knowledge; } \\
\text { Locating supports; } \\
\text { Preparing a glossary; } \\
\text { Considering interlocutors' needs; } \\
\text { Selecting unit of interpretation. }\end{array}$ \\
\hline Execution & $\begin{array}{l}\text { Previewing: processing input and formulating the last chunk } \\
\text { simultaneously in real time; } \\
\text { Noting possibilities, equivalences; } \\
\text { Bridging gaps. }\end{array}$ \\
\hline Evaluation & $\begin{array}{l}\text { Checking congruence of two versions; } \\
\text { Checking consistency of usage. }\end{array}$ \\
\hline Repair & $\begin{array}{l}\text { Refining by consulting dictionaries, thesaurus; } \\
\text { Consulting experts, sources. }\end{array}$ \\
\hline
\end{tabular}

Figure 2. Steps in mediation (CEFR 87-88)

These steps in mediation can be aligned to the classroom scenario proposed above in a systematic way. Thus, taking into consideration the limited experience of law students at this stage of their studies, in the Planning stage students are given the relevant law rather than being asked to find it themselves. They are provided with the relevant Section of the New Civil Code ( $§ 2946$ NOZ). The text is in Czech because the New Civil Code came into force on January 1, 2014 and the official authorized translation is not yet available. In actual classroom practice, this fact has led to some expression of dissatisfaction among the students (to quote a complaint from one female student "Why the hell does she not give us the law in English?"). This comment on the use of Czech material is interesting because it indicates that some students are not accustomed to interlanguage communication in their English classes, where they expect all communication to be carried out in English. However, the use of the Czech material makes the task even more authentic: it forces students to try to deal with the situation, just as real lawyers currently have to under similar circumstances. At this stage, students can use both the internet and printed law dictionaries. As regards the anticipated knowledge level of the interlocutors, the students are instructed to expect that their "clients" are native speakers of English with no knowledge of Czech language or Czech law. At this level and with this kind of basic task, the eventual discrepancies between Civil and Common law are disregarded because the focus is on the practice of mediation. 
In the Execution stage, the students - after having processed the input - perform the actual task, namely the lawyer-client interview. If necessary, they are asked to bridge any gaps that may occur in the communication. The "clients" want to know if the hotel in which their valuables had been stolen should compensate them for the loss they incurred. The "lawyers" inform the clients about the relevant law and about how it relates to their case. They advise them of what steps need to be taken next.

The Evaluation and Repair stages are more difficult to perform with speaking tasks such as the one described above. The problem has been dealt with by adding a continuation to the task, in which the students switch roles, with the "lawyer" becoming the "client" and vice versa. This gives the students the chance to check congruence and consistency. If necessary, they can carry out any repairs since the student who had previously played the role of the client can carry out his or her own legal analysis and check the research done by the student roleplaying the lawyer previously. To meet these criteria, the second role play is designed to mirror the first one: despite some slight changes in the scenario, the relevant law that is used in the analysis and the mediation remains the same.

The "Hotel Room Theft" activity serves as a good example of a task aimed at the practice of the skill of mediation. Framed by the Czech legal context, it stimulates students to fulfil the task of text processing in expertto-layman communication in a meaningful and realistic way.

\section{Conclusion}

As argued in the paper, the communicative skill of mediation has been unjustly overlooked in EFL/ESP classrooms. Mediation is a complex communicative skill that concerns the processing, transmission, modification of information in a foreign language as well as one's own language, and calls for the speaker's monitoring of the recipient's reactions to assure proper understanding. In this sense, mediation fits well into the recent conceptual shift of the ELT paradigm, namely the current 'socio-dynamic period' of motivation that is "characterized by a concern with dynamic systems and contextual interactions" (Ushioda and Dörnyei 2012: 396).

Mediation, as a specific communicative skill requiring the rendering of information by a lawyer to his or her client in order to enable them to make an informed decision, has an important role in the teaching of Legal English. As demonstrated with the practical activity designed for the practice of this skill, mediation can involve both interlanguage and intralanguage 


\section{Barbora Chovancová}

communication, realistically attesting to the complexity of interactions in the modern professional world.

\section{R E F E R E N C E S}

Alcaraz, Enriquie and Brian Hughes (2014) Legal Translation Explained. Abingdon and New York: Routledge.

Chovancová, Barbora (2013) "From classroom to courtroom: Preparing legal English students for the real world". In: Vystrčilová, Renata (ed.) Právní jazyk - od teorie $k$ praxi (Legal Language: From Theory to Practice). Olomouc: Palacký University.

Chovancová, Barbora (2014) "Needs analysis and ESP course design: Self-perception of language needs among pre-service students". Studies in Logic, Grammar and Rhetoric 38 (1): Issues in Teaching and Translating English for Specific Purposes (ed. by Halina Sierocka and Halina Swieczkowska), 43-57.

Chromá, Marta (2004) Legal Translation and the Dictionary. Tübingen: Max Niemeyer Verlag.

Chromá, Marta et al. (2011a) New Introduction to Legal English, Revised Edition. Volume I. Praha: Univerzita Karlova.

Chromá, Marta et al. (2011b) New Introduction to Legal English, Revised Edition. Volume II. Praha: Univerzita Karlova.

Common European Framework of Reference for Languages: Learning, Teaching, Assessment. Language Policy Unit, Strasbourg www.coe.int/lang-CEFR, http://www.coe.int/t/dg4/linguistic/source/framework_en.pdf

Do, Coyle, P. Hood and D. Marsh (2010) CLIL: Content and Language Integrated Learning. Cambridge: Cambridge University Press.

Dendrinos, Bessie (2006) "Mediation in communication, language teaching and testing". JAL 22, 9-35. http://rcel.enl.uoa.gr/KPGnew/texts/Dendrinos_me diation\%20JAL.pdf

Dörnyei, Zoltán (2007) Research methods in applied linguistics: Quantitative, qualitative and mixed methodologies. Oxford: Oxford University Press.

Dudley-Evans, Tony and Maggie Jo St John (1998) Developments in English for Specific Purposes: A Multi-disciplinary Approach. Cambridge: Cambridge University Press.

Howatt, A.P.R. and Henry G. Widdowson (2004[1984]) A History of ELT, 2nd ed. Oxford: Oxford University Press.

Hutchinson T. and A. Waters (1987) English for Specific Purposes. Cambridge: Cambridge University Press.

Krois-Lindner and TransLegal (2006) International Legal English. Cambridge: Cambridge University Press.

Krois-Lindner, Matt Firth and Translegal (2008) Introduction to International Legal English. Cambridge: Cambridge University Press. 
Long, Michael L. (2005) Second Language Needs Analysis. Cambridge: Cambridge University Press.

Mehisto, Peeter, David Marsh and María Jesús Frigols (2008) Uncovering CLIL: Content and Language Integrated Learning in Bilingual and Multilingual Education. Oxford: Macmillan.

Pym, Anthony (2012) On Translator Ethics: Principles for Mediation between Cultures. Amsterdam and Philadelphia: John Benjamins.

Pym, Anthony (2015) "On Literacy and Translation" A plenary speech at Creating, Shaping, Signifying: 10th Brno Conference of English, American and Canadian Studies. January 2015. Brno: Masaryk University.

Šarčević, Susan (1997) New Approach to Legal Translation. The Hague: Kluwer Law International.

Sierocka, Halina (2014) Legal English. Warszawa: C.H. Beck.

Ushioda, Ema, and Dörnyei, Zoltán (2012) "Motivation". In S. Gass \& A. Mackey (Eds.), The Routledge handbook of second language acquisition (pp. 396409). New York: Routledge.

Usó-Juan, Esther and Alicia Martínez-Flor (2006) "Approaches to language learning and teaching: Towards acquiring communicative competence through the four skills". In: Usó-Juan, Esther and Alicia Martínez-Flor (eds.) Current Trends in the Development and Teaching of the Four Skills. Berlin: Mouton de Gruyter, 3-25.

Valero-Garcés, Carmen (n.d.) "Mediation as translation or translation as mediation? Widening the translator's role in a new multicultural society". http://www.translationdirectory.com/article324.htm 